科 学 通 报

\title{
哺乳类胎盘的细胞通透性及其遗传学意义 ${ }^{*}$
}

\author{
吴晓辉 $* *$ 颜永杉*** \\ (中国科学院邀传研究所, 北京 100101)
}

\section{关链词压胎发育、细胞通过胎盘、沶记染色体、母体与胎儿、白血病感染}

哺乳类母代与子代之间物质交换是通过胎盘进行的, 但双方保持相当的独立性. 近年来, 已证实人胎儿淋巴细胞通过胎盘进人孕妇的血液 ${ }^{[1]}$. 在其他哺乳类, 如猪、牛和兔等也都有 同样的发现 ${ }^{23}$. 既然胎儿细胞可通过胎盘进人母体, 那么母体的淋巴细胞或白血病细胞是否 也可以通过胎盘进入胎儿体内, 并引起母子代之间白血病的直接感染? 尽管至今国内外发现 一些白血病母子代传递的家族, 但这种母子代相继发病的机制仍不清楚. 为了证实胎盘的细 胞通透能力是否具有双向性, 即母体细胞也可以通过胎盘进入胎儿体内, 本实验以小四纯系 No.615 为动物模型, 将带有明显遗传标记的白血病细胞株 L615注人同品系孥鼠体内, 在胎儿 或出生的幼鼠体内寻找这些被注人的 L615 细胞, 来研究胚胎发育时期母体细胞通过胎盘的通 透性, 不同孨期对这种细胞通透性的影响, 以及母代与子代之间白血病的直接感染. 由于每个 L615 细胞都带有一条标记染色体 ( $B_{j}$ 染色体), 很容易与母体细胞区分开. 同 时, L615 细 胞是白血病细胞, 不论在小鼠体内或体外培养都能不断增殖传代 ${ }^{[3]}$. 因此, 即使极少量 L615 细胞通过胎盘进人胎儿体内, 也可以通过将胎儿细胞悬液(含有 L615 细胞) 注人健康的 No. 615 小鼠体内, 让 L615 细胞继续增殖使小鼠患白血病的方法测定出来. 国内外未见报道.

\section{1 材 料与方法}

\subsection{L615 细胞株在同品系 No.615 小鼠体内传代}

取 No.615 白血病小鼠的脾脏, 用 $0.9 \%$ 生理盐水制成细胞悬液 (约 $10^{6}$ 细胞 $/ \mathrm{ml}$ ). 取健康 的 No.615 小鼠, 在前肢腋下或腹腔注人 $0.2 \mathrm{ml}$ 上述细胞悬液. 在接种后 $6-6.5$ 天, 小鼠死于 白血病.

\subsection{L615 细胞通过胎盘进人胎儿体内的实验}

(1) 尔鼠体内接种 L615 细胞. 在妊娠第 7-15 天的不同孕期, 往孕鼠体内注入 $0.2 \mathrm{ml}$ L615 细胞悬液 (约 $2 \times 10^{5}$ 细胞), 并定期观察孕鼠的发病过程.

(2) 胎鼠体内 L615 细胞的检测. 本实验采用小鼠体内接种传代的方法检. 测 L615 细 胞. 即在孕鼠接种 L615 细胞后的第 4 或第 5 天, 若幼鼠尚未出生, 则用断颈法处死孕鼠. 小 心取出连着胎盘的胎鼠, 用大量 $0.9 \%$ 生理盐水洗 2-3 次. 剪断脐带, 用生理盐水洗 6 次, 以 洗去可能混入的孕鼠血液 L615 细胞(指非通过胎盘的 L615 细胞).

为了进一步检测冲洗干净的胎鼠体外是否还混有个别的母体血液 L615 细胞, 我们把最 后一次的冲洗胎鼠的生理盐水(在表 1 中称为胎鼠清洗液), 经腹腔注人健康的 No.615 小鼠 1993-03-11稳, 1993-05-20收修改稿.

*国家自然科学基金资助项目.

**本文为吴晓诨硕士论文的一部分.

*** 通许咲系人. 
(倠雄各半), 定为对照组,观察这些小鼠是否会患白血病.

将上述洗净的胎鼠畆碎,制成细胞悬液,经腹腔注人 3-4 只健康的 No. 615 小鼠, 继续 饲养. 对患白血病的小鼠进行染色体分析, 鉴定是否有 $B_{j}$ 染色体.

按 Klein ${ }^{[4]}$, Jonasson ${ }^{[5]}$ 和颜永杉 ${ }^{(6)}$ 报道的方法, 凡接种后三个月仍无肿㿔(癌)发生者, 视 为致癌阴性. 由于正常 No. 615 小鼠脾重为 $0.03-0.09 \mathrm{~g}^{\mathrm{t3} 3}$, 如果未患白血病小鼠脾重超过 $0.10 \mathrm{~g}$, 我们也进行染色体分析.

\section{3 骨和脾脏细胞中期染色体制备和染色体分带}

（1）中期染色体直接制片. 往小鼠腹腔注人适量秋水酰胺, 取骨髓和脾脏细胞.按空气干 燥法制片。

（2）脾脏细胞体外短期培养制备染色体片子. 若白血病小鼠死亡不久, 我们将脾细胞接 种在 RPMI 1640 培养基(含 $10 \%$ 小牛血清),在 $37^{\circ} \mathrm{C}$ 培养 $1 \mathrm{~h}$,再制备染色体片子.

（3）染色体 C-带处理. 按照我们先前报道的方法进行染色体 C-带处理 ${ }^{[3]}$.

\section{4 镜检监定 L615 细胞}

选择分散好、染色体 $2 n-40$ 的分裂相, 观察是否有 $B_{i}$ 染色体. 在 150 个分裂相中未 能发现有 $B_{j}$ 染色体者,定为致癌阴性, 即无 L615 细胞经过胎盘进人胎儿体内.

\section{2 结果与讨论}

\subsection{L615 细胞通过胎盘进人胎儿体内引起母子代之间白血病直接感染}

从表 1 可以看出,在第 1 至 VI 实验组中,注人 L615 细胞的孕鼠, 其胎鼠细胞悬液都可 使被接种的健康小鼠患白血病, 即在被接种小鼠的骨髓和脾脏都已找到带有 $\mathrm{B}_{1}$ 染色体的细胞 (即 L615 细胞) (图 1), 并且它们的脾脏很大, 达 0.45- $1.26 \mathrm{~g}$ (图 2). 但是, 它们的对照组, 即所有用胎鼠清洗液接种的小鼠已存活超过三个月, 至今仍全部存活 (III 实验组除外). 在 III 实验组中,我们在接种胎鼠清洗液后 12 和 19 天, 杀死被接种的小鼠,进行染色体分析, 在 150 个分裂相中均未发现 $B_{j}$ 染色体; 而且脾重平均仅为 $0.09 \mathrm{~g}$, 均在正常 No. 615 小鼠 脾 重的范围. 对照组这些多次重复的结果可以排除本实验因清洗不够, 混人㖻鼠血液 中 L615 细胞的可能性. 因此, 我们首次证朋了白血病细胞可以通过胎盘进人胎儿体内,引起母子代之 间白血病直接感染. 这也为目前尚不清楚的白血病母子代传递的发病机制提供了直接证据.

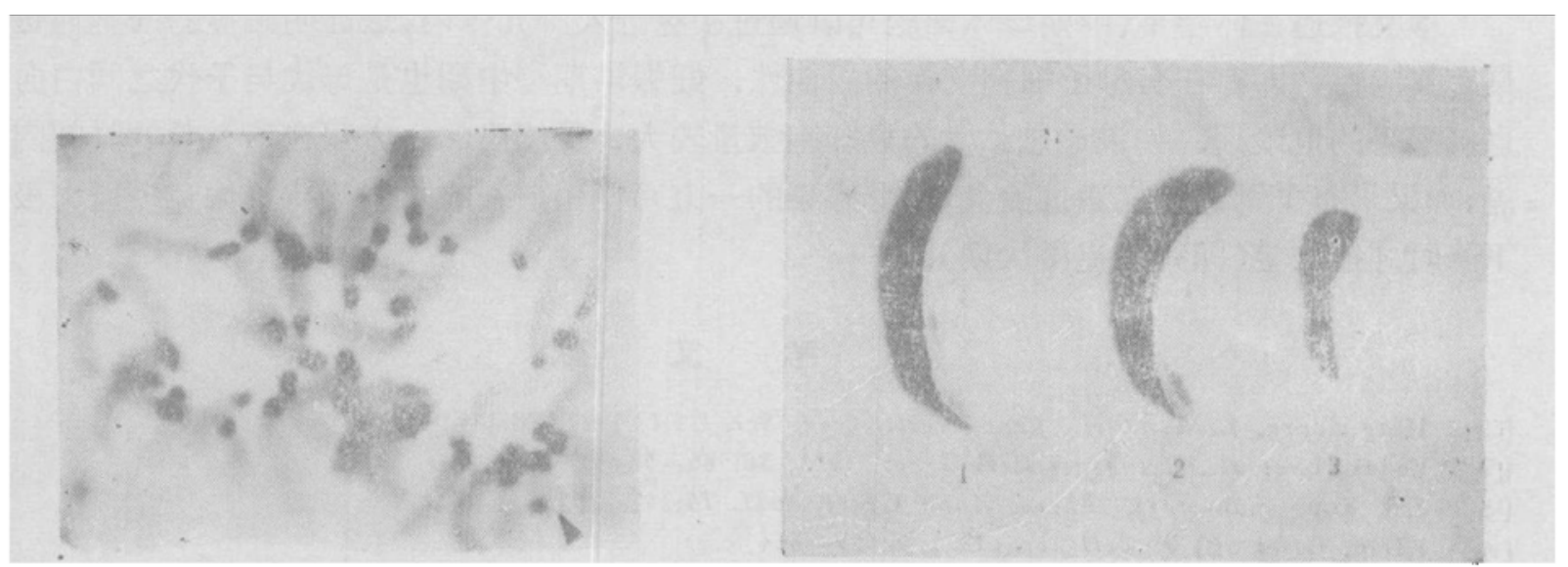

图 1 胎鼠体内 L615 细胞 管头所示为 $B_{1}$ 染色体,第 19 号染色 体长璔末端有一个大的异染色质区
图 2 No. 615 小燚脾脏大小的比较 1.白血病小鼠，2.在妊㡎早、中期接种

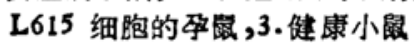


表 1 白血病你鼠胎儿体内 2615 细胞的检测

\begin{tabular}{|c|c|c|c|c|c|c|c|c|c|}
\hline \multirow{2}{*}{$\begin{array}{l}\text { 实 } \\
\text { 俭 } \\
\text { 合 }\end{array}$} & \multicolumn{3}{|c|}{ 好鼠注入 L615 细胞 } & \multicolumn{3}{|c|}{ 胎翺体内 L613 细胞检测 } & \multicolumn{3}{|c|}{ 对照组 } \\
\hline & $\begin{array}{c}\text { 注人 L615 细胞 } \\
\text { 时的娶期 } \\
\text { (天) }\end{array}$ & $\begin{array}{c}\text { L615 细胞仼小 } \\
\text { 成内传代时间 } \\
\text { （天） }\end{array}$ & $\begin{array}{l}\text { 㿞圂 } \\
\text { 脾重 } \\
\text { (g) }\end{array}$ & $\begin{array}{c}\text { 注人胎鼠细胞后 } \\
\text { 小最存活时间 } \\
\text { (天) }\end{array}$ & 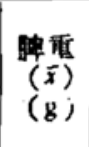 & $\begin{array}{l}B_{1} \text { 染 } \\
\text { 色体 }\end{array}$ & $\begin{array}{c}\text { 注入胎鼠清洗液 } \\
\text { 小鼠存活时间 } \\
\text { (天) }\end{array}$ & $\begin{array}{l}\text { 髅重 } \\
(\bar{x}) \\
(\mathrm{g})\end{array}$ & $\begin{array}{l}B_{1} \text { 杂 } \\
\text { 色体 }\end{array}$ \\
\hline I & 7 & 5 & 0.52 & 12 & 0.45 & + & $\left.>90^{\circ}\right)$ & - & - \\
\hline II & 8 & 4 & 0.68 & 8 & 0.55 & + & $>90$ & - & - \\
\hline $1 ! 1$ & 8 & 5 & 0.73 & $8-9$ & 0.52 & + & $12-19^{61}$ & 0.09 & - \\
\hline iv & 9 & 5 & 0.39 & 12 & 1.26 & + & $>90$ & - & - \\
\hline $\mathbf{v}$ & 9 & 5 & 0.39 & 10 & 0.46 & + & $>90$ & - & - \\
\hline V1 & 12 & 4 & 0.36 & 8 & 0.62 & + & $>90$ & - & - \\
\hline vil & 13 & 5 & 0.45 & $7-84$ & 0.14 & - & $>90$ & - & - \\
\hline
\end{tabular}

a) 动物至今仍存活.

b) 在注入胎鼠清洗液 12 天和 19 天,处死小臤，监定是否有 $B$, 染色体.

\section{2 胎盘的细胞通透性与努期胚胎发育时期有关}

我们的实验结果表明: 怀扔第 7 天至第 12 天注人 L615 细胞, L615 细胞可以通过胎盘 进人胎儿体内; 但在伓孕第 15 天注人 L,615 细胞(表 1 中 VII 组), 尽管李鼠患白血病死亡, 脾重达 $0.45 \mathrm{~g}$ (为正常 No. 615 小鼠平均值的五倍), 其胎鼠细胞都未能使被接种的小鼠患白 血病(脾重仅为 $0.14 \mathrm{~g}$, 在骨髓和脾脏均未能发现 L615 细胞). 因此, 我们的实验证明了胎盘 的细胞通透性与胚胎发育阶段密讱相关: 在怀孕早、中期, 胎盘有较强的细胞通透性; 在怀桑 后期, 胎息这种细胞通透性明显降低, 甚至消失.

胎盘的这种细胞通透性在不同妊娠时期出现明显的差异,这很可能与胎盘的结构有关.在 怀孕早、中期, 胎盘从形成到逐步趋于完善, 母体的淋巴细胞或白血病细胞, 有可能通过胎盘 进人胎儿体内; 而在妊娠后期,胎盘结构已完善, 母体的细胞就不易通过胎盘进人胎儿体内.

\section{3 胎盘的细胞通遊性是双向性,而不是单向性}

如前面所述, 在人和动物母体血液中发现有胎儿淋巴细胞, 表明胎儿细胞可以通过胎盘进 入母体, 即单向性. 但在胚胎发育过程中, 胎儿细胞如何和何时通过胎盘进入母体? 仍是胚胎 发育生物学有待解决的重要课题.

本文报道在怀孕早、中期母体细胞可以通过胎盘进人胎儿体内,这证明胎盘的细胞通透性 具有双向性, 即存在有母子细胞交换的可能性. 妊娠早期和中期也是母代与子代之间白血病 直接感染的危险期. 如果通过胎盘的癌细胞数量较大, 受感染的一方可在不太长的时间内致 癌; 如果只有个别癌细胞通过胎盘, 那受感染的一方可能用很长的时间等待机体免疫能力极度 下降时才能致癌(即有癌症潜伏期).

\section{孝文献}

[1] Hergenderg, L. A. el al., Proc. Natl. Acad. Sci. USA, 1979, 76:1453-1455.

[2] Redek, 1. et al., Cytogenet Cell Genet, 1983, 36:580-584.

[3] Yan Yong-shan et al., Theor. Appl. Genet, 1987, 74:247-252.

[4] Klein, G. et al., J. Cell Sci., 1971, 8:659-664.

[5] Jonasson, J. es al., J. Cell Sci., 1977, 24:217-223.

[6] 硕水汽,遭传学报, 1983,10(3): $209-215$. 